\title{
Primary Healthcare and diabetes management in the rural
}

\section{communities}

\author{
Edmond I Anowa $^{1 *}$, Ezekiel U Nwose ${ }^{1,2}$, Samuel D Nwajei ${ }^{1}$, Helen Chime ${ }^{1}$, Solomon E.O. Egwenu ${ }^{1}$ and Eunice O Igumbor $^{1}$ \\ ${ }^{1}$ Department of Public and community Health, Novena University Ogume, Nigeria. \\ ${ }^{2}$ School of Community Health, Charles Sturt University, New South Wales, Australia
}

*Corresponding Author: Edmond Anowa. Department of Public and community Health, Novena University Ogume, Nigeria. Tel: +234 8052218651.

Received date: Augusł 22, 2020: Accepted date: August 24, 2020: Published date: September 09, 2020

Citation: Edmond I Anowa, Ezekiel U Nwose, Samuel D Nwajei, Chime H., O. Egwenu S. E. and Eunice O Igumbor (2020) Primary Healthcare and diabetes management in the rural communities; J Clinical Medical Reviews and Reports. 2(7); DOI: 10.31579/2690-8794/039

Copyright: () 2020, Edmond Anowa, This is an open access article distributed under the Creative Commons Attribution License, which permits unrestricted use, distribution, and reproduction in any medium, provided the original work is properly cited.

\begin{abstract}
Primary health care (PHC) was conceptualized to play a 'central hub' role in health systems. Diabetes care services are presently unavailable in PHC facilities, except the screening programs that are carried out by non-governmental organizations. This implies there is issue of behavioural change wheel $(\mathrm{BCW})$ of the stakeholders including the quartet of ministry of health, hospital management board, healthcare professionals (HCP) and diabetes patients. This narrative review investigates perception of stakeholders towards scaling-up of a diabetes context of PHC agenda in Delta State Nigeria. The study utilized data from ongoing studies including opportunistic and purposive sampling designs. Data from published literatures on Nigeria were also reviewed. The various stakeholders' perceptions is that motivation is poor across board. The ministry of health as well as the hospitals management board, but not patients, have the capacity. Suggested ways of improving $\mathrm{BCW}$ in the state include increased allocation for the ministry of health, and retraining healthcare professionals. Others improvement measures including tackling socio-cultural beliefs, and taboos are suggested. Scaling-up and sustaining diabetes care program at the PHC level in Delta State is agreed to be the responsibility of all stakeholders. There is need to enhance capacity/knowledge among community members living with diabetes, and opportunity/practice among the HCPs, but most importantly attitude/motivation of all stakeholders.
\end{abstract}

Keywords: behavioural change wheel, central hub role, diabetes care, primary healthcare, delta state nigeria

\section{Introduction}

It is known that primary health care (PHC) was conceptualized to bring equitable quality health services to every nook and cranny of communities. Citizens are aware of PHC, but they mostly access the services at secondary healthcare levels. Employees at the PHC are aware of their responsibilities as community healthcare workers, but some are probably unware of non-invasive risk assessments they could do or subconscious of their services being rarely accessed. The management including supervisors of PHCs know the limited services being offered at the sites, but the willingness to improve is a thing of ongoing discussion [1].

Many rural dwellers are probably unaware of scope of services available to the PHCs. The employees at the sites are unaware that community members do not know the scope of services available or what other capacities they have. The management including supervisors of PHCs do not know what communication gaps exist with the target beneficiaries of their facilities. The prevailing factor has been articulated as a gap between what PHC should be and what it currently seems (Table 1).

\begin{tabular}{|l|l|l|}
\hline SN & What it should be & What it currently seems \\
\hline 1 & Attend to a wide range of health issues & Handling only a few 'First aid' issues \\
\hline 2 & Central hub for healthcare system & $\begin{array}{l}\text { Isolated facilities without established 'referral' line of } \\
\text { communication with 2nd \& 3rd tier levels }\end{array}$ \\
\hline 3 & $\begin{array}{l}\text { Mediator of 2-way communication between patients and their } \\
\text { clinicians }\end{array}$ & $\begin{array}{l}\text { 1-way 'community health worker to patient' } \\
\text { communication for 'First aid' intervention }\end{array}$ \\
\hline 4 & $\begin{array}{l}\text { Broad scope of services including preventive medicine, health } \\
\text { promotion, early diagnosis and disease management }\end{array}$ & Providing 'First aid' treatment \\
\hline 5 & Multidisciplinary 'professional' healthcare team & Non-professional care 'for the poor' \\
\hline 6 & $\begin{array}{l}\text { Adequately equipped with human and material resources to } \\
\text { provide 'value-for-money' quality services }\end{array}$ & $\begin{array}{l}\text { Unequipped; hence unacceptable poor quality cheap } \\
\text { services }\end{array}$ \\
\hline
\end{tabular}

Table 1: Description of PHC in general versus what it currently seems [2] 
With regards to contextualizing primary healthcare of diabetes, the PHC can be described as illustrated (Figure 1). However, a confounding gap in knowledge, attitude and practice is that when community members do not access the PHC, employees have virtually no service to render. The implication is lack of need to demand for resources by staff from management. This leads too little monetary and personnel provision being allocated to the site. The effect is controversy whereby the people complain of inadequate equipment of the PHC.

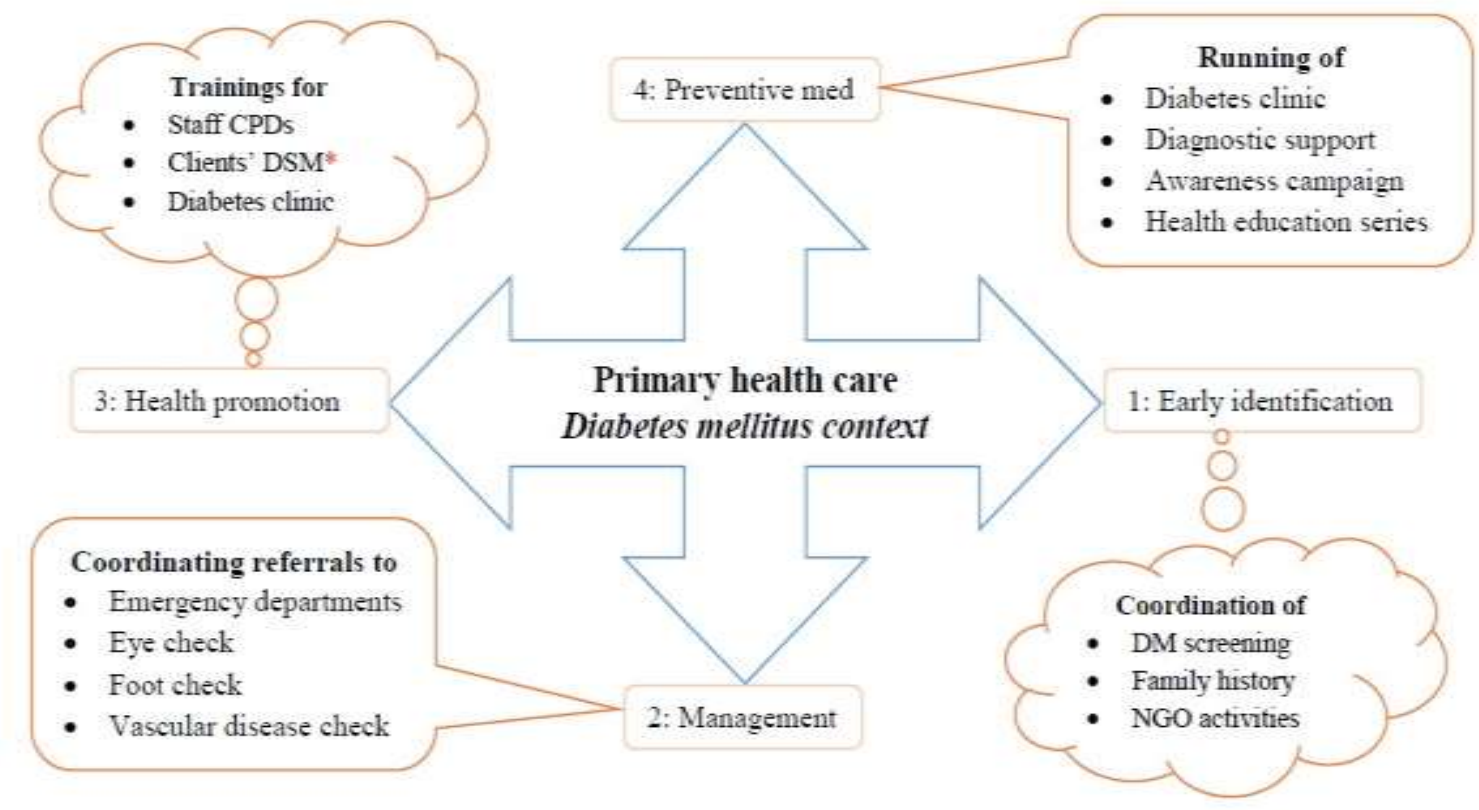

*Including patient-centred care concepts and peer-education - e.g. evaluations of beliefs, cultures and affordances for lifestyle options

Figure 1: Diabetes context of PHC description

Therefore, to reactivate PHCs in rural communities of Delta state for improved diabetes services; there need to advocation of behavioral change wheel among both benefactors are beneficiaries of the PHC facilities, especially for community members to access available services. This will necessarily require a 'community needs assessment', which is evaluation of stakeholders.

\section{Methods of the evaluation of stakeholders}

This narrative review utilized pieces of descriptive studies including opportunistic and purposive data [3-5]. The opportunistic study was carried out in the University, when stakeholders are various health professionals who attended take-off workshop of the Bringing Research in Diabetes to Global Environments and Systems (BRIDGES 2) program. The data collection were based on a standard questionnaire that assessed perceptions of 'capacity, motivation and opportunity' on Likert scale of 'poor, fair or good'. Verbal responses of the respondents in the workshop group discussions were documented [4]. Purposive survey involved ' $\mathrm{N}=$ 85 ' who attended 'training the trainers' workshops at five health facilities from 18/12/2018 - 15/01/2019. Comments of HCP about patients' behaviour were noted. The collected data were analysed thematically and using Microsoft Excel.

This evaluation of behavioural change wheel that has been ongoing was premised on the fact that beliefs and intentions are integral to running quality health services, especially in reactivation of PHC services [6]. This is with a view to adequately run diabetes clinics - i.e. where the opportunity to practice already exists in the PHC facility (Table 2).

\begin{tabular}{|l|l|l|}
\hline Do the citizens: & BCW components & Other lay terms \\
\hline Know what to access? & \multirow{2}{*}{ Knowledge is capacity } & \multirow{2}{*}{ Beliefs } \\
\hline Know how to access it? & & \\
\hline Want to do it? & Motivation driven by attitude & Intentions \\
\hline Have a chance to do it? & \multirow{2}{*}{ Opportunity to practice is based } & PHCs \\
\cline { 1 - 1 } Have direction to do it? & & 5 As \\
\hline
\end{tabular}

Table 2: The place of belief \& intentions in behavioural change wheel [6] 


\section{Results of the evaluation}

Based on the survey, it was reported that stakeholders' perceptions on capacity is good $(41 \%)$, but poor $(74 \%)$ on motivation and fair $(39.5 \%)$ on opportunity [3]. A more detailed review show for that capacity is only poor among the patients while the ministry of health and hospital management board have the capacities to deliver. However, lack of motivation cuts across all stakeholders (Figure 2). On the healthcare professional i.e. staff employed to do the job, $85 \%$ believe there is poor motivation while a relative higher $90 \%$ believe their opportunities to deliver quality services is also poor. Based on qualitative data, ways to improve $\mathrm{BCW}$ include adequate funding by the ministry of health, and continuing professional development education for the healthcare professionals amongst others (Table 3).

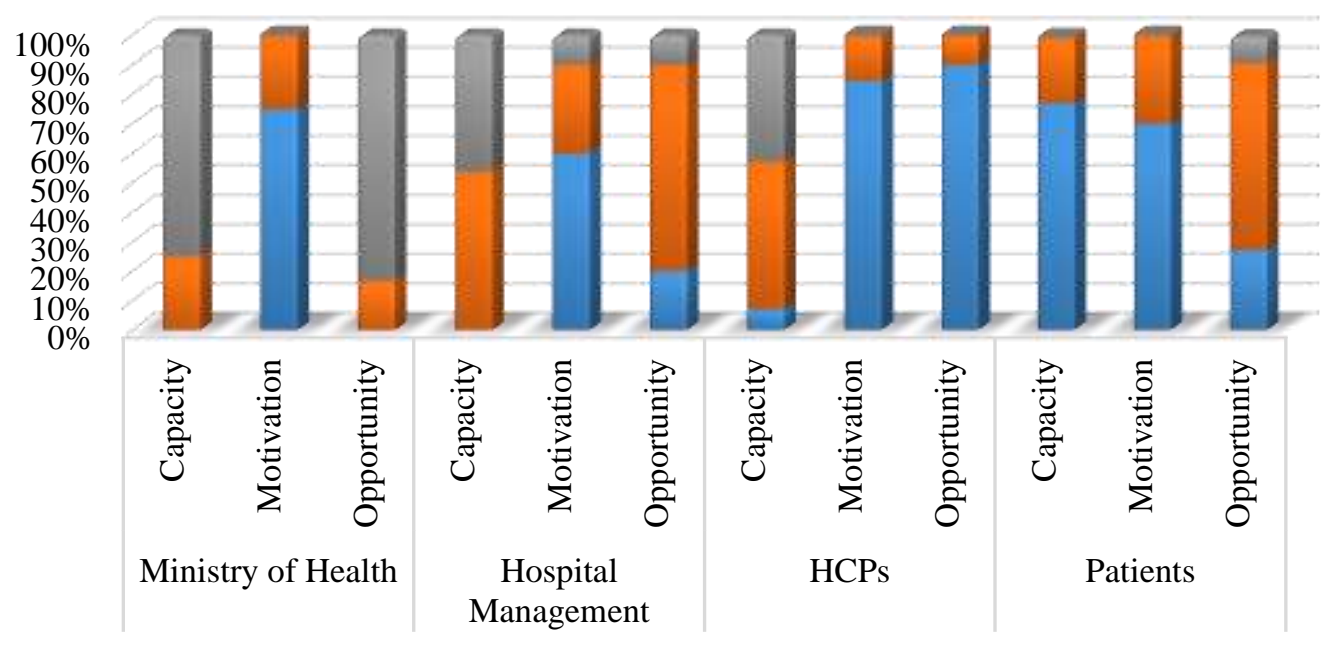

$\square$ Poor $\square$ Neutral $\square$ Good

Figure 2: Respondents' perception of stakeholders' behavioral change wheel

\begin{tabular}{|c|c|}
\hline Stakeholder & Suggestions \\
\hline \multirow{2}{*}{ MoH \& HMB } & Adequate supply of equipment \\
\hline & Increase allocation and proper monitoring of how the money is spent \\
\hline \multirow{7}{*}{ HCPs } & Giving seminars and workshops \\
\hline & Training and retraining \\
\hline & Incorporating health promotion strategy into diabetes care \\
\hline & Reduction of workload of health care practitioners \\
\hline & Adequate staffing \\
\hline & Providing Incentives \\
\hline & Report writing of work done \\
\hline \multirow{4}{*}{ Patients } & Increase awareness of diabetes management \\
\hline & Tackling socio-cultural beliefs, poverty, ignorance and taboos \\
\hline & Provision of free treatments to patients \\
\hline & As part of their education patients should be shown pictures on fliers and screens \\
\hline
\end{tabular}

Table 3: Ways to improve behavioral change wheel of major stakeholders 
It was also reported that more than half of civil servants living with diabetes declined to participate in peer-education network albeit out of fear that their public knowledge of their health condition is a threat to job security. Also, more men participated, which was contrary to sociocultural beliefs (Figure 3). Therefore, tackling socio-cultural beliefs and taboos associated with management of diabetes were suggestions for advocacy [3].
Further from brief literature review, there indication that even in tertiary health facilities, diabetes services are substandard [7]. There is report of very low level of assessment for potential complications and limited interventions in high risk cases (Figure 4). A recent report has also highlighted the need to improve on diabetes care knowledge and practice among PCPs [8].

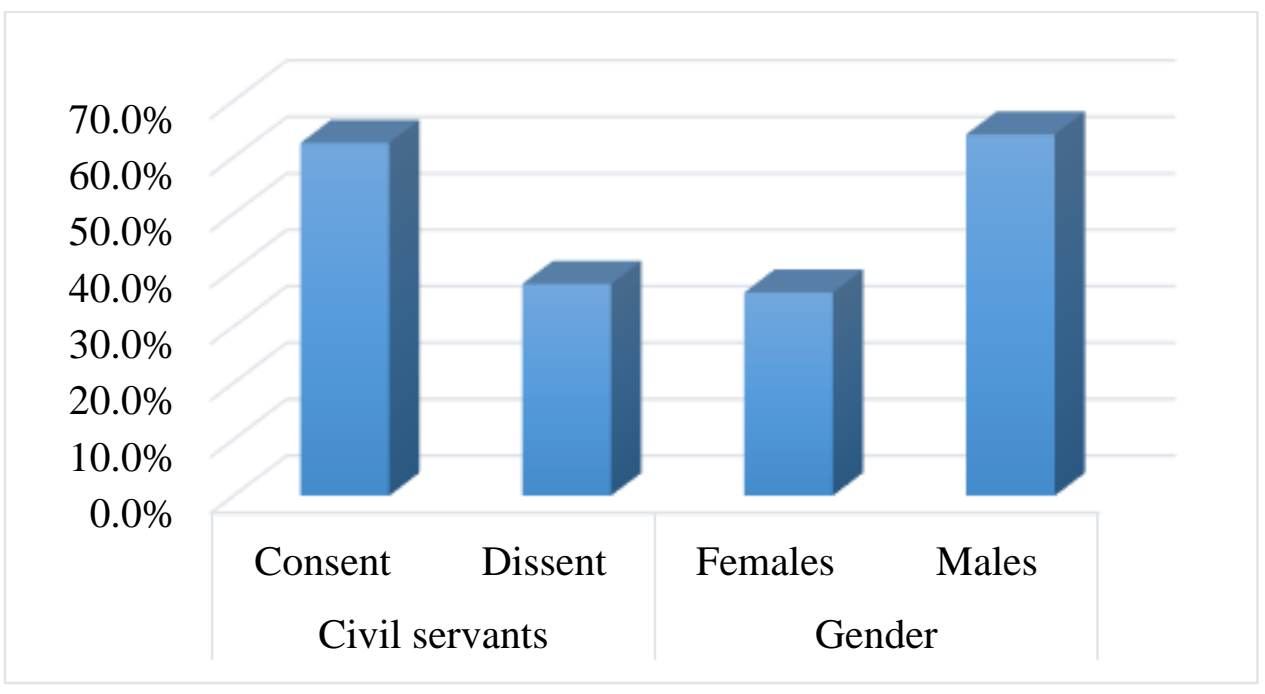

Figure 3: Distribution participants who agreed to participate in diabetes peer-education project

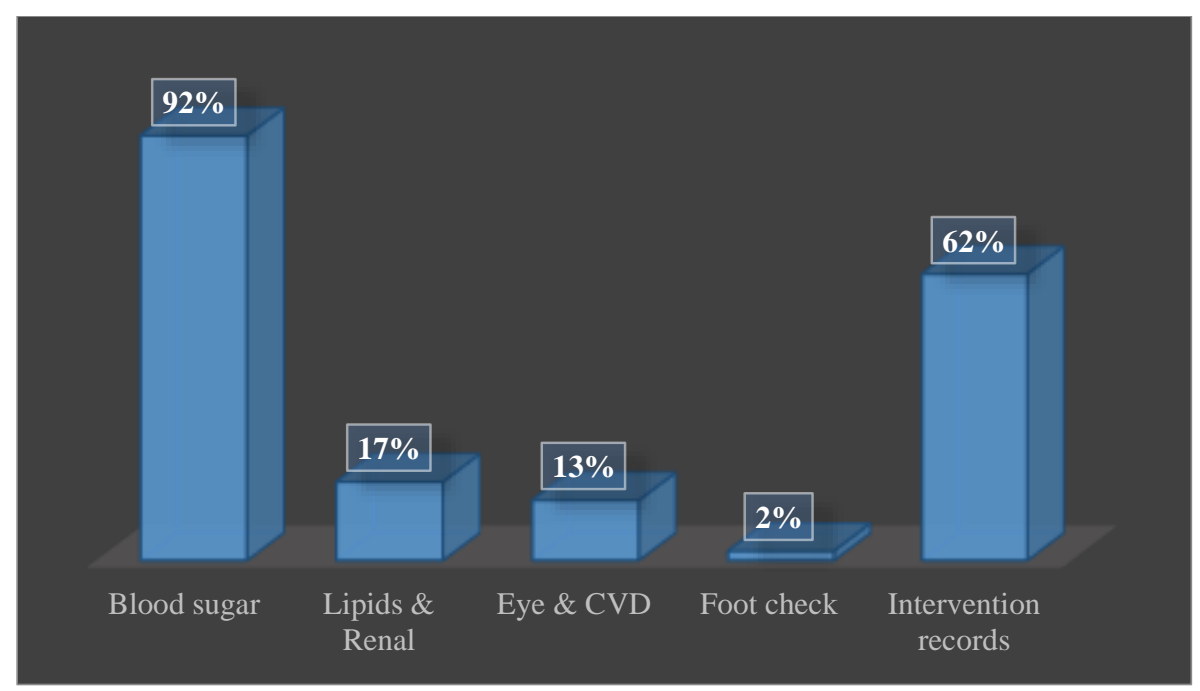

Figure 4: Reported levels of assessment for complication and intervention in high risk

\section{Discussion}

It is known that healthcare systems determine what health services are available and affordable to those that need them. In particular, the health sector is financed through different sources and the budgetary limitations determine the extent of achieving successful healthcare system. In Nigeria, universal health coverage is a desire of the government, but remains a challenge [9]. The Nigerian health delivery system comprises three tiers including primary healthcare centers (PHC) at rural communities. The primary care level is meant to be the entry point to health care services, and includes the health posts or clinics, as well as health centres with varying scopes of services covering curative, preventive, promotive, and rehabilitative services. It is estimated that more than half of the population are meant to be served by the PHC facilities [10]. For instance, diabetes self-management (DSM) education is now a cornerstone in glycaemic control and preventing cardiovascular disease (CVD) complications [11, 12], but there are still barriers in Nigeria [13, 14]. One of such barriers has recently been reported that "there is capacity to run diabetes screening and service clinic at the 
primary healthcare levels, but the limitation was incomplete patient information in the medical records" [15].

Concerted efforts have advanced diabetes care to the extent that counselors, nutritionists, physical \& health education and psychologists are now part of holistic care system. Suffice to note this underpins the concept of DSM and peer education/support that has been a research interest [16-20]. Further, the capacity, motivation and opportunity to change is synonymous with knowledge, attitude and practice, respectively $[21,22]$. It is pertinent to note that belief precedes intention, which leads to planning but depends on habits. Therefore there is need to advocate that reactivation of PHC to takes its appropriate 'central hub' role of diabetes management in Delta State is the responsibility of all stakeholders, but especially the government. The opportunities vis-à-vis facilities are available but there is need to enhance advocacy for capacity/knowledge and attitude/motivation of all stakeholders including healthcare professional, health service managers and diabetics in order to advance BCW. For instance, assessment and proper documentation of patients' weight may be attributable to healthcare personnel's attitude, but providing the reference chart can enhance motivation. Lack of knowledge of the individuals living with diabetes translates to limited capacity for self-management. Yet, re-training community healthcare workers can enhance informal peer-education process to mitigate lack of knowledge.

\section{Conclusion}

This paper critically looked into the subject of PHC with reference to its origin and meaning. As this subject was related to diabetes, the paper illustrated the PHC context of diabetes care. The narrative review utilized ongoing works done in the area of behavioural change wheel of stakeholders to articulate the capacity PHC to play a central hub role in diabetes management. It is plausible to conclude that a negative overall perception of the capacity, motivation and opportunity of the ministry of health, hospital management board, health care professional and diabetes patients to scale-up and sustain diabetes care education program in Delta State. The study recommends increased working synergy among the various stakeholders to scale-up and sustain diabetes education program in Delta State. For the ministry of health and hospital management board there should be increased allocation of resources to rising prevalent noncommunicable diseases like diabetes. For the health care professionals, more should be encouraged to specialize as endocrinologist to increase the pool of endocrinologist in the state. Also multidisciplinary approach including team work should be encouraged among health care professionals in sustaining diabetes care at health facilities. For the patients increase awareness of all aspect of the disease should embarked upon regularly while also equipping the patients with skills for selfmanagement of the disease.

\section{Acknowledgement}

This work is a doctoral preliminary review for the extension of an ongoing project. The associated data presented in the results of evaluation have been published in both conference presentations and journal as referenced. Agofure Otovwe, and Josiah Adjene from the department of Public \& Community Health in Novena University are instrumental in the work.

\section{References}

1. World Health Organization. (2008a). Nigeria still searching for right formula. Bulletin of the World Health Organization, 86, $663-665$.
2. World Health Organization. (2008b). The world health report 2008: primary health care now more than ever. NLM classifi cation: $W$ 84.6.

3. Nwose, E. U., Ejiofor, V., Agofure, O., \& Igumbor, E. O. (2019). Behavioural change wheel to scale-up intensive diabetes peereducation in Nigeria: Perceptions of stakeholders. Paper presented at the International Diabetes Federation Congress 2019, Busan, South Korea.

4. Igumbor, E. O., Agofure, O., Oshionwu, E. J., Bwititi, P. T., \& Nwose, E. U. (2019). Development of diabetes register in lowmid income country: survey of healthcare professionals' behavioural change wheel. Int J Community Med Public Health, 7, 1-8.

5. Ndubueze, P. C., Igumbor, E. O., Agofure, O., Okwelum, A. C., Ozuem, P. C., \& Nwose, E. U. (2019b). Prospects of diabetes registry and standard care at primary health facilities in Nigeria: experiential note. Int J Community Med Public Health, 7, 4.

6. Johnson, E., Bwititi, P. B., \& Nwose, E. U. (2020). Barriers to management of diabetes foot ulcer: Experiential note from a setting with free medical services. Foot (Edinb), 44, 101658.

7. Okoro, E. O., Adejumo, A. O., \& Oyejola, B. A. (2002). Diabetic care in Nigeria: report of a self-audit. J Diabetes Complications, 16, 159-164.

8. Ugwu, E., Young, E., \& Nkpozi, M. (2020). Diabetes care knowledge and practice among primary care physicians in Southeast Nigeria: a cross-sectional study. BMC Family Practice, 21, 128-128.

9. Uzochukwu, B. S., Ughasoro, M. D., Etiaba, E., Okwuosa, C., Envuladu, E., \& Onwujekwe, O. E. (2015). Health care financing in Nigeria: Implications for achieving universal health coverage. Niger J Clin Pract, 18, 437-444.

10. Uzochukwu, B. S. C. (2017). Primary health care systems (PRIMASYS): Case study from Nigeria.

11. American Diabetes Association. (2018). Introduction: National standards for diabetes self-management education - 2018. Diabetes Care, 41, S1-S2.

12. Powers, M. A., Bardsley, J., Cypress, M., Duker, P., Funnell, M. M., Fischl, A. H., et al. (2016). Diabetes self-management education and support in type 2 diabetes: A joint position statement of the American Diabetes Association, the American Association of Diabetes Educators, and the Academy of Nutrition and Dietetics. Clin Diabetes, 34, 70-80. doi:10.2337/diaclin.34.2.70.

13. Nwankwo, C. U., Ezenwaka, C. E., Onuoha, P. C., \& Agbakoba, N. R. (2015). Implementing diabetes self-management education (DSME) in a Nigerian population: perceptions of practice nurses and dieticians. Arch Physiol Biochem, 121, 123-127.

14. Ezenwaka, C., \& Eckel, J. (2011). Prevention of diabetes complications in developing countries: time to intensify selfmanagement education. Arch Physiol Biochem, 117, 251-253.

15. Ndubueze, P. C., Igumbor, E. O., Agofure, O., Okwelum, A. C., Ozuem, P. C., \& Nwose, E. U. (2019a). Prospects of diabetes registry and standard care at primary health facilities in Nigeria: experiential note. Int J Community Med Public Health, 7, 144 147.

16. Tang, T. S., Funnell, M., Sinco, B., Piatt, G., Palmisano, G., Spencer, M. S., Heisler, M. (2014). Comparative effectiveness of peer leaders and community health workers in diabetes selfmanagement support: results of a randomized controlled trial. Diabetes Care, 37, 1525-1534.

17. Liu, Y., Han, Y., Shi, J., Li, R., Li, S., Jin, N., . . Guo, H. (2015). Effect of peer education on self-management and psychological status in type 2 diabetes patients with emotional disorders. $J$ Diabetes Investig, 6, 479-486. 
18. Lauckner, H. M., \& Hutchinson, S. L. (2016). Peer support for people with chronic conditions in rural areas: a scoping review. Rural Remote Health, 16, 3601.

19. Peimani, M., Monjazebi, F., Ghodssi-Ghassemabadi, R., \& Nasli-Esfahani, E. (2017). A peer support intervention in improving glycemic control in patients with type 2 diabetes. Patient Educ Couns, 101, 460-466.

20. Debussche, X., Besancon, S., Balcou-Debussche, M., Ferdynus, C., Delisle, H., Huiart, L., \& Sidibe, A. T. (2018). Structured peer-led diabetes self-management and support in a low-income country: The ST2EP randomised controlled trial in Mali. PLoS One, 13, e0191262.
21. Johnston, M. (2017). Using behaviour change theory and techniques in implementation research. Paper presented at the The 4th Biennial Society for Implementation Research Collaboration conference, Seattle.

22. Nwose, E. U., Digban, K. A., Anyasodor, A. E., Bwititi, P. T., Richards, R. S., \& Igumbor, E. O. (2017). Development of public health program for type 1 diabetes in a university community: preliminary evaluation of behavioural change wheel. Acta Biomed, 88, 281-288.
Ready to submit your research? Choose Auctores and benefit from:

* fast, convenient online submission

* rigorous peer review by experienced research in your field

* rapid publication on acceptance

* authors retain copyrights

* unique DOI for all articles

* immediate, unrestricted online access

At Auctores, research is always in progress.

Learn more www.auctoresonline.org/journals/clinical-medical-reviewsand-reports 